\title{
Study Abroad and the City: Mapping Urban Identity
}

\section{Scott Blair ${ }^{1}$}

\section{CEA Global Education}

The city as we imagine it... soft city of illusion, myth, aspiration, and nightmare, is as real, maybe more real, than the hard city one can locate on maps in statistics, in monographs on urban sociology and demography and architecture.

Jonathan Raban

We're all pilgrims on the same journey — but some pilgrims have better road maps.

Nelson Demille

The sentiments of Raban and Demille capture something essential about how the study abroad student encounters the 21 st century city. On the one hand, the city is a physical and cultural construct of such infinite complexity that visitors to it, including study abroad students, have difficulty getting their bearings: becoming disoriented is inescapable. The city thus shapes experience. On the other hand, the city is a collective, social, and living invention itself shaped by historically contingent economic, political, and cultural forces, which, if one has the appropriate maps, guides and mental dispositions, can indeed help reveal the human rationality and internal logic that determined the city's shape, life, and meaning. In addition, the city and corresponding myths about it - City of Light, Eternal City, Sex and the City, even the Emerald City of $\mathrm{Oz}$ - are all very powerful attractions to students today.

Indeed, much of international education depends upon this very fact. Study abroad by U.S. students, despite recent growth into non-western and rural destinations, often remains focused on cities, often very large and highly urbanized ones. While the destination cities for study abroad are located across the globe, European cities remain predominant, and thus, this article focuses on study abroad in one such city. In 2007-2008, for example, over 40.6 percent of American participants studied in four European countries and their major cities. (Bhandari, 2009) Students sojourn to these urban 
places precisely because of the concentrated experiential and intercultural learning they provide, of both the academic and non-academic kind. Both experience and intuition tell us that the impulse behind this reverse "pilgrimage" to European cities is generated as much by the "hard city" of carved stone and timber as it is by the "soft city" of sweet illusion and myth. Thus, the challenge for study abroad professionals becomes: how to help students acquire conceptual maps for navigating complex urban spaces and analytical tools for understanding their many meanings. Because students must learn new ways of studying their urban milieu, while simultaneously plotting a personal course through it and becoming a part of it, they must use the city as a living and learning laboratory. As Soja writes: “...it is widely (and almost unavoidably) acknowledged that things take place IN cities, but with a few prominent exceptions... rarely have social theorists recognized that cities in themselves have a causal impact on social life, that the historical development of human societies does not just take place in cities but is also, in significant ways, generated FROM cities, and more specifically from the stimulus of urban agglomeration.” (2003, p. 275)

The very purpose of study abroad is greatly magnified in the city precisely because the city provides so many of those challenges and opportunities required of effective pedagogical strategies in cultural awareness. Identity formation, exclusion, affiliation, and community are all concepts that students encounter in concentrated forms in the modern city. One author writes, "[...] urban life has become almost completely globalized, as cities now extend their reach to the global scale in ways that have never before been imagined." (Soja, 2003) "Major cities have emerged as a strategic site not only for global capital but also for [...] the formation of transnational identities." (Sassen, 1998, p.xxx) Indeed, the city articulates cultural, social and economic forces in ways that challenge traditional notions of, and tolerance for, how people express identity and find a sense of belonging in the urban complex. Students abroad, of course, face this reality every day.

Cities give access to museums, monuments, libraries, and diverse cultural expressions and study abroad instructors often include study excursions around these when designing general academic programming and specific course content. This strategy appears to be effective; indeed, students widely report in course evaluations and post-program feedback that such activities helped them understand, appreciate, and situate in-class lectures; distin- 
guished their study abroad courses from similar ones at their home institutions; and were the most memorable part of their study abroad experiences. But cities offer much more. The study of "outsiders" or marginalized constituencies in the urban mix, for example, can be particularly fruitful. Urban sociologist Saskia Sassen argues: "Those who lack power-those who are disadvantaged, who are outsiders, who are members of minorities that have been subjected to discrimination - can gain presence in global cities, presence visà-vis power and presence vis-à-vis each other." (Sassen, 2003, p. 25)

The question, then, is how to use all the resources of study abroad host cities in ways that are culturally and geographically specific, are inter-culturally relevant, and in the end, foster the intercultural learning that is a principle aim of study abroad. This article thus looks at how experiential learning activities can be employed to support greater tolerance for diversity in an era of globalization by using a case study from a study abroad course on the urban landscapes of LGBT communities in Paris. Drawing on National Society for Experiential Education (NSEE) guidelines for experiential learning, this a article 1) proposes a theoretical approach to using the city as a laboratory for facilitating intercultural learning, understanding identity formation, and building tolerance of diversity; anda 2) shows how mapping can be used to better understand the complexity and specificity of urban landscapes and the identities they generate.

\section{Theoretical Considerations: Experiential Education}

Most study abroad instructors in urban locations are simultaneously enthused and overwhelmed by the learning opportunities centuries-old cities present to their students. However, no matter their academic field, instructors are able to identify for their students (guided as they generally are through city streets, urban parks, municipal buildings, museums and monuments) practical and visible examples of knowledge and theory directly related to core concepts of the instructors' individual disciplines. They may be challenged, however to make comprehensible to their students the complexity, apparent confusion, and chaotic accumulation of historical, sociological, and material evidence that modern cities display. This is particularly true when students are unfamiliar with the host city and its culture and perhaps altogether new to urban life and its basic structures and organizing principles. 
The National Society for Experiential Education (NSEE) has drafted and adopted Eight Principles of Good Practice for All Experiential Learning Activities. These provide one way to respond to this key dilemma. The principles adapt well to the specific goal of getting study abroad students involved in, and learning about, their city surroundings. Both common-sensible and theoretically well-grounded, NSEE principles ask instructors, before taking their students out of the quiet, well-designed and appropriately furnished classroom into the noise, distractions and discomforts of urban on-site instruction, to consider the following: intention; preparedness and planning; authenticity; reflection; orientation and training; monitoring and continuous improvement; assessment and evaluation; and acknowledgment (NSEE, 2010). Authenticity may be the most crucial of these concepts. For NSEE authenticity means that the student is placed in real world settings (outside the classroom) whose richness conveys personal meaning and impact.

NSEE principles give instructors and students shared responsibility for experiential learning. Instructors must design and facilitate authentic learning experiences, while students must actively engage as learners. Together students and instructors build a pedagogical relationship that is learningoriented, mutually empowering, and experientially anchored. Of course, implementing active learning pedagogies requires careful thought and planning. Experienced study abroad instructors recognize how hard it is to ensure that the onsite experience intentionally leads to knowledge that could not be acquired without it and that students:

- have a pre-established foundation upon which they build meaning out of the experience,

- know what desired learning outcomes they are working toward,

- think deeply about the experience before, during and after the fact,

- receive instructor feedback during the experience so that they can gauge improvement,

- be evaluated on the outcome of their effort to build knowledge upon the experience, and

- conclude that the knowledge they gained is both real and useful.

Moreover, if study abroad in the city is ideal for experiential education, and if we believe in the soundness of NSEE principles for experiential learning, then we need to encourage instructors to apply these in ways that 
demonstrate that student learning abroad is more potent because it takes place in a foreign environment, because it takes outside of the classroom, and because it draws from urban cultures very different from their own.

With this end in view, this article discusses how NSEE principles and practices can be integrated into effective onsite study. Using mapping as a strategy for this, it includes a template, drawn from an actual study abroad course. Essentially a mini-syllabus for a day, it alerts both students and instructors to the need to prepare well for the excursion and maintain a high level of concentration throughout to ensure that the experience and attendant learning will be meaningful. What instructor has not been deflated in the onsite setting upon finding students, hands in pockets, utterly ill-prepared to participate and learn? Detailed preparation, guidelines and tasks send a compelling message to students that their active participation and performance are both required and subject to instructor assessment. While the NSEE principles are not a check list to be mechanically applied, they are useful for guiding the spirit and approach to integrate experiential learning activities into their courses. In short, when NSEE best practices in experiential education are employed, onsite instruction in busy urban centers has a much better chance of being successful.

\section{Theoretical Considerations: Urban Maps}

We began with the premise that many study abroad students are unfamiliar with complex urban landscapes, much less European ones (Kelly, 2009, p. 22). Our case study introduces elements of map-making into experiential pedagogy as a means of strengthening students' visual, interpretive, communicative and sociological skills - these are crucial to understand how people from different cultures use and conceive urban space. Maps can be a powerful tool for mediating the relationship between the study abroad student and the city. Maps record and store huge amounts of information and provide a means of organizing, analyzing and conveying it. They situate relationships, associations and connections-often quite obscure ones-over varied dimensions of space, time and culture. Maps often offer hidden perspectives, thus helping one become aware of deeper structural realities nearby. They form a kind of specialized language, with both "syntax" and "grammar," involving subtle nuance, implicit expression, and discrete contours of meaning. Maps propose orientation, direction, location, and distance. They are abstract images of a thousand self-spoken words. Taken together, these qualities are strikingly close to the very attributes and 
abilities we seek to inculcate in study abroad students. Maps, in short, combine both medium and message. It is surprising, then, that map-making and mapstudy remain such untapped resources in study abroad.

Getting students enthused about maps is, of course, another thing. American students today increasingly rely on directional GPS systems, eliminating the need for critical observation and problem-solving when encountering unfamiliar places. (Instructors might want to grapple with this reality and find ways of putting the smart-phone wonder of Google Maps and Google Earth to creative use as their students explore study abroad cities on foot.) However, European city maps such as those published by Michelin, or by the Topography Service of Paris' municipal government, feature great detail, legibility and esthetic beauty. At the very least, students should receive instruction in map-reading and mapmaking along with more focused technical help on the use of certain online map applications, which they can later use in their study abroad courses to chart their own ideas of what the city is, how it evolved, and why it is structured as it is. For students who grew up in small towns or even suburban areas, and for whom maps were largely unnecessary, pedagogical strategies using maps offer geographical guidance as well as insight into urban realities that otherwise might remain hidden (Kelly, 2009, pp. 30-35).

The Paris case study presented below highlights a distinct process of urban identity formation and spatial appropriation and suggests how an intentional use of maps, both in class and onsite, serves as an instructional support. Indeed, it will be seen that mapping is a particularly effective tool for teaching study abroad students about the complex forces behind city design and construction, but particularly about how minority groups both respond to and influence such forces. Other subjects less obviously suitable to mapping could nevertheless benefit from it when approached with creativity and imagination. Instructors may customize their approaches to using a map-based approach to teaching about the city according to their disciplines, the purpose here is to illustrate how the pedagogical use of maps can promote experiential learning in the study abroad city.

\section{Case Study: Mapping Identity in Gay Paris}

Our case study on mapping urban identity comes from a course called Gay Paris: Culture, Society, and Urban Sexual Identity, an investigation of the cultural, social, and literary histories of homosexual identity in the Paris context. 
Paris is a unique urban place, functioning as a "canonical capital city" for many French citizens. Further, Paris's most recent gay neighborhood Le Marais serves as a "canonical gay reference or lieu de mémoire for many of France's homosexual citizens" (Provencher, 2007, pp. 152-153). Before World War I, the earliest contemporary concentrations of gay citizens were located in Montmartre, a district already known for its "anarchism, Bohemianism and illicit sexuality." The interwar years saw gay population migrating to the Champs-Elysées district on the Right Bank and near Montparnasse on the Left. Postwar existentialist Paris found gays relocating to Saint-Germain-des-Prés before returning to the Right Bank near the Opéra and Palais Royal quarters in the 1970s. The most striking urban shift of this population, however, took place in the 1980s and 1990s when gay populations from both Paris and the provinces relocated en masse to the Marais quarter between the Bastille and the Pompidou Center, where welllit bars, opening into the street and intentionally visible, announced that French homosexuality was fully out of the closet (Provencher, 2007, pp. 155-156). Gay Paris scholar Michael D. Sibalis similarly claims that the Marais district, both a social and commercial space where gays find a sense of belonging and community, reads like an "open book" celebrating and affirming gay visibility:

[...] Le Marais shapes and sustains a nascent gay community. The quarter's venues are much more than highly profitable businesses to the men who frequent them. They facilitate sociability and reinforce solidarity among men who share a sexual orientation. (Sibalis, 1999, p. 36)

Even more interesting for study abroad students seeking an understanding of how collective identities are acquired, shaped and protected both within groups and across "competing" groups, Sibalis reminds us that .”. . the inhabitants of Le Marais remain socially, ethnically and sexually a highly diverse group, including (among others) bourgeois families of old French stock, orthodox Jews from Eastern Europe or North Africa and much more recent immigrants from the Far East." (Sibalis, 1999, p. 34) It is this demographic diversity and shifting pattern of group migration, all within the context of strongly affirmed identities, that makes the Marais quarter-but a few square kilometers - the sociological laboratory it is for experiencing and understanding how cross-cultural integration is negotiated. 
The Gay Paris course begins with an examination of the formations and constructions of sexual identity as framed in Paris over the past 100 years and continues with a survey of the relevant theoretical underpinnings of sexuality and sexual identity. This gender studies course is specifically designed to be taught in central Paris in the very heart of the Marais district, still home to one of the most densely populated LGBT communities in Europe. An integral part of the course involves mapping the urban landscape of LGBT communities, both geographically over the twenty arrondissements of the city and temporally across the 20th century, as LGBT populations discreetly migrated from quarter to quarter.

Throughout the semester, students begin building the intellectual superstructure of the course by creating and using two maps that help them situate the course content while linking it to course learning objectives: one map is of gay Paris and the other is of lesbian Paris. Both are large 31/2 by $2 \frac{1}{2}$ foot mounted maps. Commercial maps of Paris serve as a neutral backdrop that the students then "fill-in" with commentary, collage, photography, inserts, symbols, directional indicators and keys. The annotated maps pinpoint and reflect gay and lesbian urban spaces, community centers, and locales in the contemporary city space, both geographically and temporally, that students find significant. Students chart past focal points for historical gay and lesbian citizens of the city, many of whom were literary or art figures who, through their experience in Paris, exerted considerable influence on the history of ideas. Thus, the maps teach students how gay and lesbian individuals and communities, within a variety of contexts, situate themselves in urban spaces they occupy and shape. Through creating and using these maps, students begin to see gay Paris (and perhaps the larger city that hosts it) as a multi-faceted personality occupying the very different geographical spaces that it did in the course of the 20th century. The course instructor reports as well that the city of Paris actually becomes a sort of figure or character in class. (Greta Schiller's award winning documentary of interwar lesbian artistic circles, Paris Was A Woman [1995] is screened in class and reinforces the anthropomorphic impulse students have towards the city.) The different ways students have conceptualized the gay or gendered identity of Paris is expressed in the maps they create. For example, one semester found a class of particularly ambitious students agreeing to create five distinct physical maps: 
1. Contemporary Gay Paris centered on The Marais

2. Contemporary Lesbian Paris

3. Historical Gay Paris (rainbow-color coding indicates how centers of gay life have shifted in the 20th century.)

4. Literary Gay/Lesbian Paris (based on the Modernist period.)

5. ACT UP / AIDS Map (follows two important homosexual movements in the 20th century along with their influence on Paris's urban space.)

To help students understand the value of mapping urban spaces as an effective tool for learning about urban cultures, local residents from the gay and lesbian community meet with students to present their own insights into the identity of Gay Paris. Drawn from various backgrounds and nationalities, these individuals had been previously asked to think about and then draw their own maps of Gay Paris for presentation to the class. The research of Denis Provencher for Paris and Darren Kelly for Dublin (Kelly, 2009) has demonstrated the cross-cultural insights this exercise can reveal. Provencher writes: "Similar to the way French gays and lesbians perform homosexual identity by making ambiguous claims to same-sex preference during their coming-out stories, French homosexuals perform the tension between the global (Anglo-American) and local (French) when drawing their maps of gay urban terrain" (Provencher, 2007b, p. 43). Provencher's more recent and extensive work, Queer French: Globalization, Language, and Sexual Citizenship in France, serves as the Gay Paris course textbook and introduces students to over a dozen additional maps of gay and lesbian Paris they can use in both their daily personal lives and in their study of Paris sociology (Provencher, 2007a, pp. 149-191). Provencher sets out to answer, among others, the following questions relevant to student cross-cultural learning in urban spaces: what it means to be gay in France and Paris; how this meaning differs from American urban experience; how various forms of "Frenchness" affect sexual identity; and how sexual citizenship influences and is influenced by urban space. Students study the maps Provencher's research subjects have drawn up for them so as to better shape their own ideas about the forms urban mapping may take.

To acquire geographical and historical knowledge of the spatial shifts 
Gay communities in Paris have experienced in the 20th century and to encourage students to survey in situ the terrain of urban gay communities, past and present, students set out on weekly study excursions organized by the instructor. These may, for example, follow the trajectory of a lesbian novel set in Paris and read in class (Djuna Barnes' Nightwood). More traditional study excursions to gay authors' homes, bookstores, cafés and other social venues where fellow modernists and lesbians of the 1920's convened, have also been introduced into the course as has formal participation in Paris street marches for fighting AIDS and supporting Gay Pride. Where possible, this additional information is added to the maps. To reinforce a student's appreciation and awareness of urban structure and organization, all such study excursions strive to integrate map-making and map awareness in the context of authentic locations and within the context of NSEE principles of good practice in experiential education.

The template that follows is an example of this sort of excursion, in this case to the Marais quarter, a current hub of LGBT life in Paris.

\section{Gay Paris: The Marais Quarter Onsite Study Excursion}

\begin{tabular}{|ll|}
\hline Course Title: & Meeting Point: \\
\hline $\begin{array}{l}\text { Gay Paris: } \\
\text { Culture, Society, and Urban } \\
\text { Sexual Identity }\end{array}$ & North façade of the Centre Pompidou \\
\hline Course Number: GEN 330 & Meeting Time: 10:00 am \\
\hline & $\begin{array}{l}\text { Contact Information: } \\
\text { Instructor: Dr. D. Jones }\end{array}$ \\
Study Center: 45 83 14 77 & \\
\hline
\end{tabular}

Description: This onsite study excursion takes you through the principal streets of the Marais district where, through both directed and team-based learning, you will identify and analyze those discrete characteristics of the social and urban fabric that have rendered this part of the city so congenial to the gay population of Paris over the past three decades. Through your own powers of observation, supported by both maps and personal photography, you will seek to catalog the social, economic and cultural make-up of selected streets or blocks in the quarter so as to better understand how the urban space of the Marais both influences identity and is shaped by it. You will also explore the Rue des Rosiers, the heart of the Jewish Quarter, along with the neighboring religious sites and 
related cultural manifestations, In addition, you will study the quarter's surrounding physical structures and road network, the relationship of specific buildings to the neighboring quarter, the architectural styles you encounter, and the significant ways that the quarter's past is linked to today's cultural and commercial livelihood, as well as to the diverse resident communities. Finally, you will think about and appraise the sustainability and longevity of the Marais quarter as the current social center of Gay Paris. While the quarter is economically alive and currently expresses the aspirations and ambitions of its diverse populations, what forces do you find at work that might lead to significant change in the quarter's make-up and urban identity?

\section{Learning Objectives:}

- Discern through the extant urban buildings, street layout, and accompanying map the structure and organization of the Marais quarter Identify and chart on your map the commercial, social, and cultural presence of distinct communities affirming their identity in this quarter Identify and explain reciprocal influences between place and identity as experienced in the Marais

Locate and explain examples of inter-community collaboration and cooperation in the quarter

Identify and read the social iconography \& discrete historical references in the Marais district

Place particular monuments in their historical context and to describe their significance, past and present

Generate pertinent insights into the lifestyles manifested by each community

Hypothesize why the Paris Gay community chose a quarter untouched by Haussmann for its home

Instructional Format: You will learn about the Marais through a number of instructional techniques, all of which are supported by the readings and assignments that you must complete before the start of this excursion. To begin, the instructor will, at specific times, verbally identify and describe certain places, monuments and buildings representative of the quarter, both past and present. Please stay within close earshot at these times. Take notes as you would in class and ask questions or make observations that reveal that you are making progress on the day's learning objectives. At other times, you will explore and 
analyze, individually or in small groups, specific streets, commercial establishments, historical sites, or architectural elements you encounter or must locate. Use the map provided to both locate and situate important places and catalog the information you acquire directly on to this map. The specific things you must see, analyze and retain are stipulated in the instructions below or in the package of documents provided to you last week. In certain instances, you must photograph particular sites, businesses, or architectural elements. Keep your camera ready. At the end of the session, everyone will re-group and the instructor will make concluding comments, query you on your findings and put to you additional questions and assignments for the next class meeting.

Form of Assessment: In addition to a reflection paper in which you discuss the relationship between urban place/space and social identity, the instructor will collect and evaluate the materials, ideas and writings you have gathered during the study excursion and in preparation for it. You will be evaluated on the amount of information you compile; the accuracy of the information you present; and the significance you ascribe to the facts and ideas you have integrated into your work. All your work must reveal a mastery of the day's learning objectives and of the course learning objectives that they support. You must archive all excursion documentation and answer sheets for final evaluation.

\section{Required Readings:}

(These must be completed before the study excursion begins.)

Denis Provencher, Queer French: Globalization, Language, and Sexual Citizenship in France. Burlington: Ashgate, 2007, chaps. 3-5.

David Pinckney, Napoleon III and the Rebuilding of Paris, Princeton Paperbacks: PUF, 1972.

Linda Krause and Patrice Petro (eds.), Global Cities, Cinema, Architecture, and Urbanism in a Digital Age, New Brunswick: Rutgers, University Press, 2003, Chaps. 1-3.

Pascal Fonquernie, ParisMarais. Com and Gay Marais websites

George Sinclair, Historic Maps and Views of Paris, Black Dog: London, 2009.

Required Supplies \& Fees: Street Map of Le Marais, camera, writing platform, pencils and paper for sketching, class handouts, bottle of water, comfortable walking shoes, compact umbrella, $5 €$. 


\section{Study Excursion Instructions:}

I. Instructor Presentation: The Role of the Pompidou Center in the Renaissance of the Marais

Student Tasks:

Identify the functional color scheme of the Pompidou Center building. Note what impact the building is having on local business and populations.

3. Situate on your street map Haussmann's transformations of the Marais quarter.

II. Team Investigation: Identity and Public Space

Group Tasks:

Locate and visit the LGBT center on the Rue Beaubourg.

Acquire \& consult the Gay Paris map that the LBGT Center distributes.

Learn the mission of the LGBT center and the means employed to achieve it.

What message does the center's store window and building convey?

What is significant about the location of this center vis-à-vis the Marais quarter?

III. Team Investigation: Gay Business in the Rue Saint-Croix de la Bretonnerie

Group Tasks:

Find this street on your map and go to its west end.

Catalog on your map the individual commercial activities of this street.

Categorize this activity by the primary identity each establishment manifests (if any).

Where precisely do you find significant "frontiers" in gender or social identity in this street?

What physical structures in this street might account for the "change" in identity you encounter?

IV. Instructor Presentation: The Rue des Rosiers: Where Jewish and Gay Identities Meet

Students Tasks: 
How have the Jewish residents memorialized in their street the antiSemitism they have suffered?

Is there any sign in this street that the gay population has been a target of discrimination?

Log onto your map the many references you find in this street to the Holocaust.

How do you account for relative lack of Gay commerce in this street?

What messages do you encounter in the four bookstore windows of this street?

\section{Student Assignment: A Visual Essay on Urbanism: Past \& Present Individual Research:}

Return to the Marais quarter during the coming week and compile a photographic journal of urban identity and inter-cultural "dialog." Locate the angle of each photograph on your Marais street map. Write paragraph-long captions for each image. Be prepared to project, present and discuss your journal next week in class. Clearly link your presentation to the general learning objectives of the course syllabus and to the specific objective of the Marias study excursion. Send an e-copy of your presentation to course instructor no later than two days before next week's class. It must be available online to the entire class before you present it.

The process of compiling, organizing and anchoring the learning done over some twelve weeks of in-class course work and onsite study excursions is accomplished through the act of creating the comprehensive online e-map to which everyone has access. This involves both an individual and team effort of logging relevant information into the online map. Active contribution to building the online map helps students learn how the city is structured in general and how and why the local gay citizenry uses it as they do. Because the course began with a map-based approach to the subject, student attention is already drawn toward the city's general structure, its related organic evolution, its use of horizontal and vertical space, and its many interconnected networks of transport, utilities, communication, parks and buildings. This facilitates the making of the on-line map. Mapping Gay Paris helps students not only visualize the urban fabric of Gay Paris and its distinct constituent quarters but develop keener observational and analyti- 
cal skills for experiencing and learning about urban space in general. Thus, they begin to notice the many other identities and communities that make up Paris. Indeed, helping students become "aware of the different subgroups inhabiting maligned spaces", particularly in European cities where rich and poor and "sub-cultural populations are literally juxtaposed", is a learning objective other instructors have integrated into urban mapping courses (Kelly, 2009, p.34).

Finally, the students are required to engage in a critical examination and assessment of the mapping process itself. What do they find problematic about mapping the idea of identity? How many different versions of such identity maps can they conceptualize? As sexual citizenship cross-cuts so many other identities, how do other forms of citizenship get represented (or not) on these maps? How would a historical perspective of sexual citizenship reshape what the map looks like? These questions and others engage students in an ongoing process of reflection: about identity, sexuality, citizenship, culture, and prejudice, all within the context of the great influence cities have upon each. This stage also provides the instructor with an opportunity, in accordance with NSEE good practice, to both assess student learning and acknowledge student growth and personal development.

\section{Conclusion}

The outcome of group exercises in making maps of urban spaces and of the use people make of them, when accompanied by focused student reflection, is often encouraging. Not surprisingly, students report that the backdrop of the course - the Marais quarter and the larger city of Paris around it - provided them with authentic and meaningful experience that renders both course readings and lectures immediately relevant to their intercultural learning. One student wrote in an evaluation, "This course really benefits from being taught in Paris: we are able to go out and see where significant people lived and events happened and it really allows us to connect with the city." Reflecting on the course, another student commented, "Ventures into the city are a great aid to understanding the setting and significance of what is discussed in class." Such comments suggest that a well-designed application of NSEE principles to mapping and onsite instruction can result in learning outcomes that students themselves recognize as flowing from the intentional exploration of foreign urban spaces. For students, this is a first 
step towards learning to analyze and reflect upon similar cultural and identity-based forces at work in cities back home or elsewhere. Well-designed experiential education works.

Moreover, reflection on the mapping demonstrates its effectiveness in helping students learn to conceptualize and theorize from specific instances of spatial use and identity formation in ways that suggest real intellectual breakthrough in intercultural learning. A student concludes, "The Gay Paris model, showing us the difference between the United States and France and between Republicanism and identity politics, is not just interesting regarding LGBT but also other aspects of our society, like economics and politics." Similarly, another recent student wrote, "Coming out applies to gays, but also other areas of life." These comments reveal how students progressively come to see and critically evaluate the larger reality, political structure, and underlying prejudice of identity formation and discrimination as experienced in this specific Parisian setting. In these latter cases, the students are expressing a nascent awareness that national and cultural differences are similarly subject to ingrained notions by others of what is considered "acceptable" behavior. The students seem to be saying that understanding, and by extension facilitating, the coming out of Parisian gays, implies a personal responsibility of understanding and tolerating cultural, political, and economic differences elsewhere. The map-based analysis of the Marais, and the conclusions students draw from it, helps them apprehend, legitimize and navigate other challenging intercultural landscapes.

Mapping is not an objective activity and it is important that students recognize what is at stake in the mapping of urban identity. On the one hand, students are exposed to the dangers of typological categorization, which is never precise; and on the other, of ethnological analysis, which is exceedingly difficult even when not done in a foreign city, culture and tongue. The instructor must alert students to the methodological hazards of reductionism and interpretation in the mapping exercises. But even if these dangers are more marked in the study abroad city, so too are the benefits. The soft city of illusion, myth, and aspiration that Jonathan Raban evoked in our opening citation is also a place of liberation and escape for most Americans of study abroad age. Asked to describe more precisely the mythical attractions of the city they so passionately feel, students who had taken the course most likely would speak of illumination, permanent truths, emancipation, flight 
and self-discovery. In short, the students discover the sense of permissiveness the city creates. Not surprisingly, this is the very permissiveness that not only attracted gay and lesbian populations to Paris in the first place, but perhaps was what the students hoped to find in studying abroad. More importantly, the city's inherent reputation for such tolerance creates a vital space where student intercultural learning can take place and be freely expressed. A student's post-course comment is instructive: "The course allows a person the opportunity to freely engage with, think about, and discuss the lifestyle realities (both past and present) of a group of people it is often taboo to discuss with openness at home. This course is liberating for that." This is surely the fundamental purpose of study abroad: getting students to think about and show tolerance for different ways of thinking and being, and this because of the impact the foreign environment has had upon them.

While visiting museums, historic sites and celebrated buildings as part of study abroad no doubt results in unique, fascinating, and intrinsically meaningful learning experiences, the truly effective use of the city by study abroad educators requires - if the most is to be made of limited student time, energy, and resources - a theoretically-grounded approach that emphasizes the demographic, geographical, historical, and intercultural connectivity of the many places "visited." Case studies in urban identity suggest that the creative use of map-making and map-interpreting, when used alongside good practices in experiential education, offers students a unique way to better understand the evolution, tensions and cultural significance of the city life and corresponding urban spaces that so significantly shape both their own study abroad experience and the behavioral skills needed for negotiating the cultural differences they encounter. 


\section{References}

Bhandari, R. (2009). Open Doors 2009: Report on International Educational Exchange. New York: Institute of International Education.

Forum on Education Abroad. (2008). Standards of Good Practice for Education Abroad. Retrieved March 22, 2010, from http://www.forumea.org/ documents/ForumEAStandardsGoodPrctMarch2008.pdf

Kelly, D. (2009). "Lessons from Geography: Mental Maps and Spatial Narratives.” In E. Brewer \& K. Cunningham (Eds.), Integrating Study Abroad into the Curriculum: Theory and Practice Across the Disciplines (pp. 21-40). Sterling, VA: Stylus.

National Society for Experiential Education. (2010). Standards of Practice: Eight Principles of Good Practice for All Experiential Learning Activities. Retrieved February 20, 2010, from http://www.nsee.org/about_us.htm

Provencher, D. M. (2007a). Queer French: Globalization, Language, and Sexual Citizenship in France. Burlington: Ashgate.

Provencher, D. M. (2007b). "Mapping Gay Paris: Language, Space and Sexuality in the Marais", Contemporary French and Francophone Studies, 11(1), 37-46.

Sassen, S. (1998). Globalization and Its Discontents. New York: The New York Press, xxx.

Sassen, S. (2003). "Reading the City in a Global Digital Age." In L. Krause and P. Petro (Eds.), Global Cities, Cinema, Architecture, and Urbanism in a Digital Age (pp. 15-30). New Brunswick: Rutgers University Press.

Sibalis, M. D. (1999). "Paris." In D. Higgs (Ed.), Queer Sites: Gay Urban Histories Since 1600 (pp. 10-37). London: Routledge.

Soja, E. W. (2003). "Writing the City Spatially." City, 7(3), 269-280. London: Routledge, 1999, p. 10-37. Retrieved January 29, 2010, from http://www.brynmawr.edu/Acads/GSSW/schram/soja.pdf

\section{End notes}

1 The author wishes to thank John D. Heyl, Emilie Johnson and Denis Provencher for the thoughtful insights and contributions they brought to this article. 